\title{
Clinicopathological Variants of Breast Cancer in a Tertiary Care Hospital in Pakistan
}

\author{
Raja Najam-ul-Haq ${ }^{1}$, Raja Khalid Shabbir ${ }^{2}$, Muhammad Saad ${ }^{3}$
}

\author{
1 Associate Professor, Department of Surgery, Fauji Foundation Hospital, Rawalpindi Pakistan \\ 1 Manuscript writing \\ 2 Post Graduate Resident, Department of Surgery, Holy Family Hospital, Rawalpindi Pakistan \\ 2 Manuscript writing \\ 3 House Officer, Fauji Foundation Hospital, Rawalpindi Pakistan \\ 3 Data collection, Analysis $\mathcal{E}$ interpretation
}

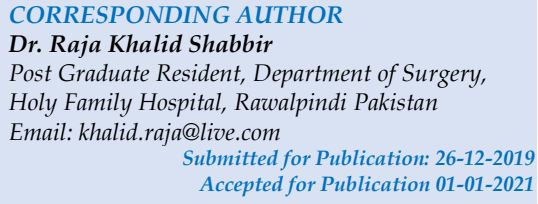

Submitted for Publication: 26-12-2019 Accepted for Publication 01-01-2021

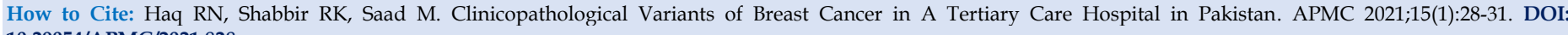
10.29054/APMC/2021.828

\section{ABSTRACT}

Background: Breast cancer is a growing phenomenon among females which has ever-lasting ramifications on the patient as well as the family. The only way of subjugating breast cancer is through an efficient and effective screening and subsequent treatment process. Objective: This study aimed at identifying the different clinicopathological patterns of breast cancer and the age group most frequently targeted by CA breast. Study Design: A prospective study. Settings: Fauji Foundation Hospital (FFH), Rawalpindi and Foundation University Medical College (FUMC) Pakistan. Duration: Six months from January 2018 to June 2018. Methodology: This study included 224 female patients, irrespective of their nationality by convenience sampling, who underwent any kind of breast surgery. The patients were evaluated according to their age, side of breast involved, site of lump in the breast, histopathology report and type of lesion (inflammatory, benign or malignant). The data was entered and analyzed using IBM SPSS version 25. Results: Our study sample of 224 individuals was found to have about 23 different histopathological variants of breast cancer. Invasive ductal carcinoma was found in almost all age groups and it was also the most common variant $(80.8 \%)$, followed by invasive lobular carcinoma $(4 \%)$. Majority of the cases were recorded in the elderly age bracket from 55 to 65 years. Right breast was found to be involved in $53.6 \%$ of the cases whereas left breast involvement was at $44.2 \% .5$ patients had lesions in both of their breasts. Upper outer quadrant was affected in $88 \%$ females followed by upper inner quadrant $(6.7 \%)$. All four quadrants were involved in only 3 patients. Conclusion: This study concluded that invasive ductal carcinoma is the commonest clinical as well as pathological type of CA breast. 181 females out of a total of 224 had invasive ductal carcinoma. Therefore, this particular breast cancer type merits our special attention. Our study further concluded that most of the breast pathologies were found in elderly females aged between 55 and 65 years.

Keywords: Clinicopathological, Histopathology, Cancer, Breast, Females, Variants, Hospital.

\section{INTRODUCTION}

The life-changing diagnosis of cancer leaves the patient and family both in great uncertainty. The global medical lexicon has come a long way in terms of diagnosing and treating different diseases but we have yet to overcome cancer in its advanced stages which often proves fatal. ${ }^{1}$ The Latin word 'cancer' literally means a 'crab' owing to the finger-like projections, more formally known as spicules, seen mostly in microscopic analysis of solid malignant tumors. The World Health Organization (WHO) states cancer as the second leading cause of death globally as nearly one in every six deaths is due to this disease. The most viable option for controlling these figures and defeating the grim cancer prognosis is the judicious usage of cancer screening. This along with widespread awareness campaigns, with the help of active media, would lead to early diagnosis of cancer, thus enabling curative surgical resection and better survival rates. $^{2}$
Breast cancer is the most common cancer in the developing world; therefore, it is of particular importance for a country like Pakistan. ${ }^{3}$ In women, the incidence of breast cancer has overhauled that of cervical cancer and has now become the most common cancer type in females. ${ }^{4}$

Breast cancer pathogenesis involves a multitude of factors ranging from genetics to lifestyle to diet and environment. Treating breast cancer, or any cancer for that matter, requires a multidisciplinary approach in which a team of surgeons, oncologists and radiologists sit together and assess tumor size, lymph node status, histopathological type of the cancer and whether the cancer has spread to distant organs or not. ${ }^{5}$ Three types of breast lesions (inflammatory, benign and malignant) target young as well as the elderly female population. ${ }^{6}$ Any pathology of the breast leaves long-lasting impact on the patient's body and mind. ${ }^{7}$ 


\section{METHODOLOGY}

Study Design: It was a prospective study.

Settings: Fauji Foundation Hospital (FFH), Rawalpindi and Foundation University Medical College (FUMC) Pakistan.

Duration: Six months from January 2018 to June 2018.

Sample Technique: Convenient sampling.

Sample Size: This study included 224 female patients.

Inclusion Criteria: All the patients who underwent any kind of breast surgery were included in the sample.

Exclusion Criteria: Poorly fixed specimens and referred cases from other cities were excluded from the study.

Data Collection Procedure: The data was collected from histopathology reports issued by pathology department of Foundation University Medical College (FUMC). Selfadministered pro forma was used to collect demographic and histopathology data by the investigators. The data was analyzed using IBM SPSS v25 and interpreted. The data was transformed into tables where applicable.

\section{RESULTS}

The study was performed in Fauji Foundation Hospital, Rawalpindi aiming to find out different variants of breast cancer in relation to their age, laterality, site and histopathology result. The findings are tabulated below.

Table 1: Age of study participants

\begin{tabular}{|l|c|c|}
\hline \multicolumn{1}{|c|}{ Age Group } & Frequency & Percentage \\
\hline $\mathbf{1 6 - 2 0}$ years & 1 & $0.4 \%$ \\
\hline $\mathbf{2 1 - 2 5}$ years & 1 & $0.4 \%$ \\
\hline $\mathbf{2 6 - 3 0}$ years & 1 & $0.4 \%$ \\
\hline $\mathbf{3 1 - 3 5}$ years & 9 & $4.0 \%$ \\
\hline $\mathbf{3 6 - 4 0}$ years & 20 & $8.9 \%$ \\
\hline $\mathbf{4 1 - 4 5}$ years & 29 & $12.9 \%$ \\
\hline $\mathbf{4 6 - 5 0}$ years & 33 & $14.7 \%$ \\
\hline $\mathbf{5 1 - 5 5}$ years & 28 & $12.5 \%$ \\
\hline $\mathbf{5 6 - 6 0}$ years & 34 & $15.2 \%$ \\
\hline $\mathbf{6 1 - 6 5}$ years & 36 & $16.1 \%$ \\
\hline $\mathbf{6 6 - 7 0}$ years & 16 & $7.1 \%$ \\
\hline $\mathbf{7 1 - 7 5}$ years & 9 & $4.0 \%$ \\
\hline $\mathbf{7 6 - 8 0}$ years & 7 & $3.1 \%$ \\
\hline Total & 224 & $100 \%$ \\
\hline
\end{tabular}

Highest number of cases were recorded in the age group. More than $30 \%$ of breast cancer patients were between 5565 years of age showing breast cancer to primarily affect old aged females. An exceptional case was that of a young female whose age was less than 20 years and who had malignant Phyllodes tumor.

\section{Table 2: Breast laterality}

\begin{tabular}{|l|c|c|}
\hline \multicolumn{1}{|c|}{ Breast involved } & Frequency & Percentage \\
\hline Right breast & 120 & $53.6 \%$ \\
\hline Left breast & 99 & $44.2 \%$ \\
\hline Both breasts & 5 & $2.2 \%$ \\
\hline Total & 224 & $100.0 \%$ \\
\hline
\end{tabular}

APMC Vol. 15 No. 1 January - March 2021
Right breast appeared to be more affected by the carcinoma. Involvement of right and left breasts were $53.6 \%$ and $44.2 \%$ respectively. Both breasts were involved in only 5 patients, more so in the older age group.

Table 3: Site of lesion

\begin{tabular}{|l|c|c|}
\hline \multicolumn{1}{|c|}{ Site } & Frequency & Percentage \\
\hline Upper outer quadrant & 198 & $88.4 \%$ \\
\hline Upper inner quadrant & 15 & $6.7 \%$ \\
\hline Lower outer quadrant & 4 & $1.8 \%$ \\
\hline Lower inner quadrant & 4 & $1.8 \%$ \\
\hline All & 3 & $1.3 \%$ \\
\hline Total & 224 & $100 \%$ \\
\hline
\end{tabular}

Upper outer quadrant was affected in $88 \%$ females followed by upper inner quadrant (6.7\%). All four quadrants were involved in 3 patients who were middle aged and had invasive ductal carcinoma.

Table 4: Histopathology of breast specimen

\begin{tabular}{|l|c|c|}
\hline \multicolumn{1}{|c|}{ Clinicopathological Variant } & Frequency & Percentage \\
\hline Invasive ductal carcinoma & 181 & $80.8 \%$ \\
\hline Metaplastic carcinoma & 1 & $0.4 \%$ \\
\hline $\begin{array}{l}\text { Recurrent invasive ductal } \\
\text { carcinoma }\end{array}$ & 4 & $1.8 \%$ \\
\hline Squamous cell carcinoma & 1 & $0.4 \%$ \\
\hline Invasive lobular carcinoma & 9 & $4.0 \%$ \\
\hline $\begin{array}{l}\text { Metaplastic carcinoma with } \\
\text { chondrosarcomatous component }\end{array}$ & 1 & $0.4 \%$ \\
\hline Intra-cystic papillary carcinoma & 2 & $0.9 \%$ \\
\hline No residual tumor & 3 & $1.3 \%$ \\
\hline Mucinous carcinoma & 2 & $0.9 \%$ \\
\hline Tubular carcinoma & 1 & $0.4 \%$ \\
\hline $\begin{array}{l}\text { Invasive mucinous colloid } \\
\text { carcinoma }\end{array}$ & 1 & $0.4 \%$ \\
\hline Paget's disease of nipple & 1 & $0.4 \%$ \\
\hline $\begin{array}{l}\text { Intraductal papilloma with } \\
\text { fibrocystic changes }\end{array}$ & 1 & $0.4 \%$ \\
\hline Malignant phylloides tumor & 1 & $0.4 \%$ \\
\hline $\begin{array}{l}\text { Metastatic papillary } \\
\text { adenocarcinoma }\end{array}$ & 3 & $1.3 \%$ \\
\hline Ductal carcinoma in situ & 2 & $0.9 \%$ \\
\hline $\begin{array}{l}\text { Invasive ductal carcinoma with } \\
\text { ductal carcinoma in situ }\end{array}$ & 2 & $0.9 \%$ \\
\hline Apocrine carcinoma & 1 & $0.4 \%$ \\
\hline Intraductal carcinoma & 1 & $0.4 \%$ \\
\hline Invasive papillary carcinoma & 2 & $0.9 \%$ \\
\hline Medullary carcinoma & 1 & $0.4 \%$ \\
\hline $\begin{array}{l}\text { Invasive ductal carcinoma with } \\
\text { ductal carcinoma in situ }\end{array}$ & 2 & $0.9 \%$ \\
\hline Invasive mammary carcinoma & 1 & $0.4 \%$ \\
\hline Total & 224 & $100.0 \%$ \\
\hline
\end{tabular}

About 23 different histopathological variants were found in our study sample of 224 female patients. Most commonly encountered finding was invasive ductal carcinoma $(80.8 \%)$, followed by invasive lobular carcinoma (4\%). Invasive ductal carcinoma was found in 
almost all age groups, with a peak between $50-60$ years age group. Interesting findings included intra-cystic papillary carcinoma, intraductal carcinoma and mucinous carcinoma which were exclusively found in females older than 70 years. Apocrine carcinoma was found in only one patient aged 66 years. One case of malignant phyllodes tumor was identified in a young female who was under 20 years of age. (discussion section is reserved for comments)

\section{DISCUSSION}

Incidence of breast cancer increases with age. Jacques Ferlay and colleagues conducted a study in 2014 which concluded with 65-74 years as the peak breast cancer incidence age group in more developed countries. ${ }^{8} \mathrm{~A}$ retrospective study carried out on Chinese patients from 1993 to 2013 also showed an increased likelihood of developing breast cancer with an increase in age. ${ }^{9}$ This trend is similar to other Asian countries. In western women, the mean age at which breast cancer is diagnosed is even higher with America at 64 years. ${ }^{10}$ A study performed at $\mathrm{CMH}$ Rawalpindi showed that the most affected age is $40-49$ years. ${ }^{11}$ In our study, highest number of cases were recorded within the age group of 55-65 years depicting that breast cancer primarily affects the elderly female population. Much older women were encountered in our setting who suffered from breast cancer.

On the other hand, a research carried out in Morocco concluded that a higher proportion of breast cancer is seen in young Moroccan women, these results were in accordance with previously published articles. ${ }^{12}$

Exceptional cases in our study were of three young females. One was under the age of 20 years and was found to have malignant phyllodes tumor while two other young women between the age of 20-30 years were diagnosed with having invasive ductal carcinoma. Breast cancer diagnosis in young females is particularly debilitating because of the many challenges faced by them such as fertility issues due to chemotherapyinduced amenorrhea and permanent menopause, declining bone density as a result of medications, young age group being a risk factor for the development of contra lateral breast cancer and psychological distress. ${ }^{13}$

As in standard literature, our research paper also supported the fact that upper outer quadrant of the breast is involved in majority of the cases. A booming $88 \%$ of our study sample had upper outer quadrant lump. A research carried out on patients in a tertiary care hospital in the Indian state of Bihar also found upper outer quadrant of the breast to be the most common site of breast malignancy.

Involvement of right and left breast in our research study were $53.6 \%$ and $44.2 \%$ respectively. Right breast was more involved than the left. Previously, it was documented that more lesions were seen in left breast than right. ${ }^{14}$

About 23 different histopathological variants of breast cancer were found in our research. Out of a sample of 224 females having some type of breast lesion, the most commonly encountered pattern was of invasive ductal carcinoma $(80.8 \%)$ followed by invasive lobular carcinoma $(4 \%)$. Invasive ductal carcinoma was found in almost all age groups with peak between age group 50-60 years. Also, 4 out of 224 cases were found to have recurrent invasive ductal carcinoma. An Indian study also had a similar trend that is out of 34 malignant breast lesions, $27(79.41 \%)$ came out to be invasive ductal carcinoma. ${ }^{15}$ Our results were further backed up by a study which took place this year in Allied Hospital, Faisalabad, Pakistan, which also depicted invasive ductal carcinoma as the most common (93\%) and invasive lobular carcinoma as the second most common (4\%) breast pathology. ${ }^{16}$

Interesting findings included intra-cystic papillary carcinoma and mucinous carcinoma which were exclusively found in females older than 70 years showing that these pathologies are associated with old age. These are in accordance with published articles showing old age predominance. ${ }^{17,18}$ Also, apocrine carcinoma was found in only one $(0.4 \%)$ patient showing its rarity. Reported incidence is low i.e., $0.4 \%$ in Korea and mean age is 51.4 years. Here it was seen in 66 years old. ${ }^{19}$

\section{CONCLUSION}

Like elsewhere in the world, invasive ductal carcinoma was the most common finding encountered. In our study 181 out of 224 female patients had invasive ductal carcinoma which emphasizes the need for our special attention towards the diagnosis and treatment of this cancer type. Furthermore, elderly female population (between ages 55 and 65) had most of the breast pathologies.

\section{LIMITATIONS}

This study was conducted in Fauji Foundation Hospital which basically caters for the families of retired armed forces soldiers. Therefore, more extensive research should be performed with larger sample size is encouraged, preferably in public setting.

\section{SUGGESTIONS / RECOMMENDATIONS}

Therefore, all clinicians should keep in mind the diagnosis of cancer whenever an elderly female patient walks in the clinic with a lump in her breast and more efforts should be directed towards the care of our elderly population.

CONFLICT OF INTEREST / DISCLOSURE

No conflict of interest is involved. 


\section{ACKNOWLEDGEMENTS}

We are thankful to our dedicated team which includes surgeons, residents, house officers, specimen delivery personnel, laboratory technicians and pathology department for assisting us at every level of this research.

\section{REFERENCES}

1. Hauken MA, Grue M, Dyregrov A. "It's been a life-changing experience!" A qualitative study of young adult cancer survivors' experiences of the coexistence of negative and positive outcomes after cancer treatment. Scand J Psychol. 2019;60(6):577-84.

2. Sharmin S, Alam S, Bhuiyan MZ, Mollah MN, Mamun-Or-Rasheed $\mathrm{M}$. Clinicopathological pattern and risk factors of carcinoma breast in younger age group. BSMMUJ. 2021;9(2):92-5.

3. Brenner $\mathrm{H}, \mathrm{Hakulinen} \mathrm{T}$. Are patients diagnosed with breast cancer before age 50 years ever cured? J Clin Oncol. 2004;22(3):432-8.

4. Gangadaran, SG. (2016 Dec;4). Lessons from a clinicopathological study of breast cancer. Int J Res Med Sci. 2016;(12):5325-8.

5. Mohapatra M, Satyanarayana S. Evaluation of clinico: pathologic findings of breast carcinoma in a general hospital in Southern India. Indian J Cancer. 2013;50(4):297-301.

6. Shrivastava JP. A Clinicopathological study of breast lumps in patients presenting in Surgery OPD in a referral hospital in Madhya Pradesh. Int J Current Microbiol \& Applied Sci. 2015;4(8):919-23.

7. Singh SK, Pankaj D, Kumar R, Mustafa R. A clinico-pathological study of malignant breast lump in a tertiary care hospital in Kosi region of Bihar, India. Int J Surg. 2016;3(1):32-6.

8. Ferlay J, Soerjomataram I, Dikshit R, Eser S, Mathers C, Rebelo M, et al. Cancer incidence and mortality worldwide: sources, methods and major patterns in GLOBOCAN 2012. Int J Cancer. 2015;136(5):E359-86.

9. Si W, Li Y, Han Y, Zhang F, Wang Y, Li Y, et al. Epidemiological and Clinicopathological Trends of Breast Cancer in Chinese Patients During 1993 to 2013. Medicine. 2015;94(26):e820.
10. Williams R, Laing AE, Demenais F, Kissling G, Gause BL, Chen V, et al. Descriptive analysis of breast cancer in African-American women at Howard University Hospital, 1960-1987. J Natl Med Assoc. 1993;85(11):828-34.

11. Naqvi SRQ, Farhat K, Naqvi SSQ, Rashid MM, Sheikh IA, Ali M, et al. Breast cancer: Clinical and histopathological features at Combined Military Hospital Rawalpindi. Pak Armed Forces Med J. 2017;67(4):540.

12. Bakkach J, Mansouri M, Derkaoui T, Loudiyi A, Fihri M, Hassani $\mathrm{S}$, et al. Clinicopathologic and prognostic features of breast cancer in young women: a series from North of Morocco. BMC Womens Health. 2017;17(1):106.

13. Domchek CA. Breast cancer in young women. Breast Cancer Research. 2010;12:212-22.

14. Singh SK, Pankaj D, Kumar R, Mustafa R. A clinico-pathological study of malignant breast lump in a tertiary care hospital in Kosi region of Bihar, India. Int J Surg. 2016;3(1):32-6.

15. Neeli D, Atla B, Seeram SK, Latchupatula L, Kamireddy SR. Clinicopathological study of breast lesions over a period of one year in a tertiary care center. International Journal of Research in Medical Sciences, 2018;6(10):3397-402.

16. Irfan S, Akram M, Rehman S, Sajid M. Clinicopathological Pattern of Breast Cancer Presentation in Allied Hospital Faisalabad. APMC. 2019;13(1):30-2.

17. Ait Benkaddour $\mathrm{Y}$, El Hasnaoui S, Fichtali K, Fakhir B, Jalal H, Kouchani M, et al. Intracystic papillary carcinoma of the breast: report of three cases and literature review. Case Rep Obstet Gynecol. 2012;2012:979563.

18. Di Saverio S, Gutierrez J, Avisar E. A retrospective review with long term follow up of 11,400 cases of pure mucinous breast carcinoma. Breast Cancer Res Treat. 2008;111(3):541-7.

19. Hur H, Ahn YJ, Park S, Kim JH, Koo JS, Park BW. Clinicopathologic Characteristics of Apocrine Breast Carcinoma. J Korean Surg Soc. 2009;77(1):43-9. 